\title{
Portfolio optimization using a hybrid of fuzzy ANP, VIKOR and TOPSIS
}

\author{
Reza Raei and Mohammad Bahrani Jahromi*
}

Department of Finance, University of Tehran, Tehran, Iran

\begin{tabular}{ll}
\hline A R T I C L E I N F O & A B S T R A C T \\
\cline { 3 - 3 } $\begin{array}{l}\text { Article history: } \\
\text { Received April 20, } 2012\end{array}$ & $\begin{array}{l}\text { One of the primary questions in asset management is to find good combinations of different } \\
\text { Accepted 21 July 2012 }\end{array}$ \\
Available online & model and this has been an interesting area of research for over half a century. The proposed \\
July 23 2012 & technique to find an appropriate portfolio. We first select some important financial criteria and \\
\hline Keywords: & then using decision makers' opinions and by implementation of some fuzzy analytical network \\
VIKOR & analysis we find appropriate weights of the asset. The proposed model uses two multiple \\
TOPSIS & criteria techniques namely TOPSIS and VIKOR and the model is examined for some real-world \\
Asset allocation & data from Tehran Stock Exchange. The results of the implementation of the proposed model \\
Tehran Stock Exchange & have been examined against Markowitz traditional model. The preliminary results indicate that \\
& the proposed model of this paper performs reasonably well compared with alternative method.
\end{tabular}

(C) 2012 Growing Science Ltd. All rights reserved.

\section{Introduction}

Stock market has always been as one of the most important issues for measuring economic circumstances. It is always a good place for people to invest by purchasing a small portion of any publically traded firm. However, finding suitable asset is a challenging task since there are always some bullish and bearish sectors. Investing is a dynamic task and investors always have to look on the market. There are always opportunities for buying or selling asset and making appropriate change on asset allocation. However, it is important to make a wise decision on time and based on facts. Kahraman et al. (2002) presented a new method for capital budgeting techniques using discounted fuzzy versus probabilistic cash flows. Ertuğrul and Karakaşoğlu (2009) presented a new method for performance evaluation of Turkish cement firms with fuzzy analytic hierarchy process and TOPSIS methods. Meziani (2003) made an assessment on the effect of investment barriers on international capital flows using an expert-driven system.

There are literally various attempts to find appropriate asset allocation on the market based on multiple criteria decision making techniques. Analytical hierarchy process (AHP) is one of the most

* Corresponding author.

E-mail addresses: m.bahrani.j@gmail.com (M. Bahrani Jahromi) 
popular techniques for ranking different alternative based on various criteria (Saart, 1980, 1996a, 1996b). Ehrgott et al. (2002) used five different objective for asset allocation problem in addition to S \& P components. Tiryaki and Ahlatcioglu (2009) used fuzzy portfolio selection using fuzzy AHP. More specifically, the decision-making problem was to decide which stocks to choose for investment and in what proportions investment must happen. They considered a two constrained fuzzy AHP methods given by Enea and Piazza (2004) and revised the model to address some of its fallacies. Then we applied the resulted modified method to the problem of choosing stocks on the Istanbul Stock Exchange and discussed their results. Chen and Hung (2009) proposed another decisionmaking method for stock portfolio selection based on computing with linguistic assessment. Lee et al. (2011) discussed that existing methodologies of equity investment, such as fundamental analysis, technical analysis, and institutional investor analysis, could explore some important factors of stock price behaviors. They provided the first analysis on the interactive relationships among the factors in incorporating the methods of Decision Making Trial and Evaluation Laboratory (DEMATEL) and Analytic Network Process (ANP). The empirical results demonstrated that factors from the existing analytical methodologies had substantial interactive and self-feedback dynamics. They reported profitability, among the key factors, as the most important one influencing investment decision, followed by growth and trading volume. In addition, due to the complexity of the ANP, they developed a new methodology to simplify the process, and empirical evidences indicated that the approach was effective and efficient.

\section{Methodology}

In order to know the experts opinion, seven managers of mutual funds were asked to give their insights on our criteria and assets that were chosen. The proposed study of this paper used Tehran Stock Exchange (TSE) for the case study and considered any publicly traded firm on this exchange whose stock shares were traded over the fiscal period of 2007-2010. The proposed model of this paper removed any alternative asset whose shares were traded fewer than 10 working days per month leaving us to consider only 56 alternatives. Next, all stocks were ranked using VIKOR and TOPSIS methods and the results were compared. Expert feedback were collected based on five criteria including profitability, liquidity, leverage, performance and market. Each category includes some ratios, which are discussed next.

\subsection{Determinants of stock selection for evaluation}

In this research five major criteria's was categorized based on research literature and experts' opinions including profitability, liquidity, leverage, efficiency and market measures.

\subsubsection{Profitability}

The first profitability criteria is return on assets (ROA), calculated as follows,

Return on Assets $(\mathrm{ROA})=\frac{\text { Net Income }}{\text { Total Assetes }}$

The second important criteria is return on equity (ROE), calculated as follows,

Return on Equities $(\mathrm{ROE})=\frac{\text { Net Income }}{\text { Total Equities }}$

The third criteria is net profit margin, calculated as follows, 
Net profit margin $=\frac{\text { Earning after taxes }}{\text { Total revenue }}$

Finally, the last criteria is operating margin, calculated as follows,

Operating margin $=\frac{\text { Operating income }}{\text { Total revenue }}$

\subsubsection{Liquidity}

Current ratio is the first criteria used, which is calculated as follows,

Current ratio $=\frac{\text { Current assets }}{\text { Current liabilities }}$

Quick ratio is the second criteria used, which is calculated as follows,

Quick ratio $=\frac{\text { Current assets-total inventories }}{\text { Current liabilities }}$

\subsubsection{Leverage}

Debt ratio is the first criteria used, which is calculated as follows,

Debt ratio $=\frac{\text { Total debt }}{\text { Current liabilities }}$

Ownership ratio is another criteria in this section calculated as follows,

Quick ratio is the second criteria used, which is calculated as follows,

Ownership ratio $=\frac{\text { Shareholders' equities }}{\text { Total assets }}$

Interest coverage ratio is another important ratio, which is calculated as follows,

Interest coverage ratio $=\frac{\text { Earning before interst and tax }}{\text { Interest charges }}$

\subsubsection{Performance ratios}

The first criteria is account receivable turnover, which is calculated as follows,

Accounts Receivable Turnover $=\frac{\text { Total Net Sales }}{\text { Accounts Receivables }}$

The second criteria is inventory turnover, which is calculated as follows,

$$
\text { Inventory turnover }=\frac{\text { Costs of goods sold }}{\text { Average inventory }}
$$


The third criteria is total asset turnover, which is calculated as follows,

Total asset turnover $=\frac{\text { Total revenue }}{\text { Total assets }}$

\subsubsection{Market}

Fama and French (1992) demonstrated that market on book value ratio could explain diversity of asset return and it is calculated as follows,

$\mathrm{MV} / \mathrm{BV}=\frac{\text { Market value }}{\text { Book value }}$

Price per earning is another important criteria, which is used on the market for asset evaluation and it is calculated as follows,

$\mathrm{P} / \mathrm{E}=\frac{\text { Price }}{\text { Earning per share }}$

Finally, ratio of profit distributed among shareholders is the last ratio used in this paper and it is calculated as follows,

$\mathrm{d}=\frac{\text { Divident per share }}{\text { Earning per share }}$

\section{Analytical network processes (ANP)}

One of the primary concerns on the implementation of traditional AHP is the interdependencies which could happen among components of hierarchy. Saaty (1996a, 1996b) extended the idea of AHP for a more comprehensive form of pairwise comparison called ANP. ANP has five stages and the first stage determines relationships and their dependencies. The second stage measures the impacts of each criterion on other criteria based on pairwise comparison and all eigenvalues and eigenvectors are calculated. All responses are gathered based on Likert scale from one to nine and geometric mean is used to find the average of all feedbacks. Therefore, we have,

$\lambda_{\max } \cdot W=A \cdot W$,

where $\lambda_{\max }$ is the maximum eigenvalue associated with matrix $A$. Third, consistency ratios are calculated and if it is less than 0.1 we can accept the results, otherwise the data are not consistent. Forth, supermatrix is established. Supermatrix concept resembles to Markov sequence process. Supermatrix can limit the coefficients to calculate all priorities, thereby cumulative effect of each element on other elements in interaction. In this phase, special vector resulting from paired comparison matrix is used as matrix weights. Internal relationships between elements/criteria are captured in a separate matrix so that supermatrix represented by $\mathrm{W}$ is created. Zero value or blank space refers to no internal relationships between elements/criteria or clusters. Fifth, the best alternative is selected. If the supermatrix created through previous phases covers all over the network, weights of priorities can be found in alternatives column in a normalized supermatrix. Raising the supermatrix to power, the supermatrix is converged and therefore its weights are stabilized. Finally, the alternative with the highest priority is considered as the first top alternative.

\section{Fuzzy set and fuzzy numbers}

A triangular number shown in Fig. 1 is represented as $(1, \mathrm{~m}, \mathrm{u})$ where $1, \mathrm{~m}$ and $\mathrm{u}$ represent the lowest, the most possible and the highest possible values, respectively where $l \leq m \leq \mathrm{u}$. Each fuzzy number can be represented by a membership function as follows, 
$\mu(x / \widetilde{M})=\left\{\begin{array}{c}0, \\ (x-l) /(m-l), \\ (u-x) /(u-m), \\ 0,\end{array}\right.$

$$
x<l \text {, }
$$

$l \leq x \leq m$,

$m \leq x \leq u$,

$x>u$

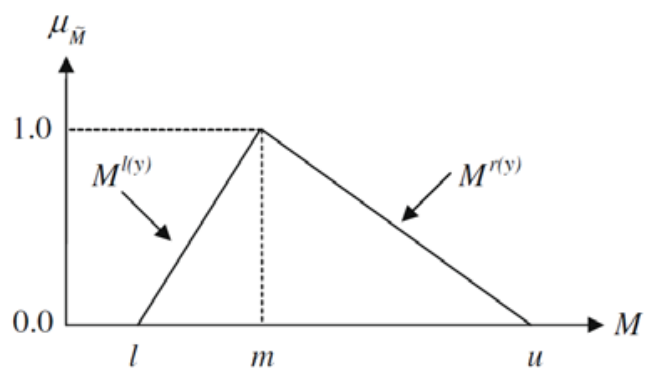

Fig.1. A triangular number

The proposed study of this paper uses the following linguistic terms to represent a triangular fuzzy number. Table 1 shows decision making numbers in linguistic form and their equivalences.

Table 1

Lingual scale used to measure intensity of importance

\begin{tabular}{lcc}
\hline Linguistic scale & Triangular fuzzy scale & Triangular fuzzy reciprocal scale \\
\hline Strongly important & $(9,9,9)$ & $(1 / 9,1 / 9,1 / 9)$ \\
Intermediate value & $(7,8,9)$ & $(1 / 9,1 / 8,1 / 7)$ \\
Moderately important & $(6,7,8)$ & $(1 / 8,1 / 7,1 / 6)$ \\
Intermediate value & $(5,6,7)$ & $(1 / 7,1 / 6,1 / 5)$ \\
Weakly important & $(4,5,6)$ & $(1 / 6,1 / 5,1 / 4)$ \\
Intermediate value & $(3,4,5)$ & $(1 / 5,1 / 4,1 / 3)$ \\
Equally important & $(2,3,4)$ & $(1 / 3,1 / 3,1 / 2)$ \\
Intermediate value & $(1,2,3)$ & $(1,1,1)$ \\
\hline Just equal & $(1,1,1)$ & \\
\hline
\end{tabular}

The proposed model of this paper uses Chang's method $(1992,1996)$ for fuzzy network analysis, which has easier implementation compared with fuzzy AHP. Let $X=\left\{x_{1}, x_{2}, \ldots, x_{n}\right\}$ be the vector of different alternatives and $U=\left\{u_{1}, u_{2}, \ldots, u_{m}\right\}$ is the vector of various objectives. Based on Chang's method for each objective we define the following,

$M_{g i}^{1}, M_{g i}^{2}, \ldots, M_{g i}^{m}, \quad i=1,2, \ldots, n$

where $M_{g i}^{j}(j=1,2, \ldots, m)$ are fuzzy numbers.

First step: The fuzzy numbers are defined as follows,

$S_{i}=\sum_{j=1}^{m} M_{g i}^{j} \otimes\left[\sum_{i=1}^{n} \sum_{j=1}^{m} M_{g i}^{j}\right]^{-1}$

Then we have

$\sum_{j=1}^{m} M_{g i}^{j}=\left(\sum_{j=1}^{m} l_{j}, \sum_{j=1}^{m} m_{j}, \sum_{j=1}^{m} u_{j}\right)$ 
Therefore, we have,

$\sum_{i=1}^{n} \sum_{j=1}^{m} M_{g i}^{j}=\left(\sum_{i=1}^{n} l_{i}, \sum_{i=1}^{n} m_{i}, \sum_{i=1}^{n} u_{i}\right)$,

and the inverse of Eq. (21) is defined as follows,

$\left[\sum_{i=1}^{n} \sum_{j=1}^{m} M_{g i}^{j}\right]^{-1}=\left(\frac{1}{\sum_{i=1}^{n} u_{i}}, \frac{1}{\sum_{i=1}^{n} m_{i}}, \frac{1}{\sum_{i=1}^{n} l_{i}}\right)$

Step 2. In order to compare two fuzzy numbers we use the following

$V\left(M_{2} \geq M_{1}\right)=\operatorname{SUP}\left[\min \left(\mu_{M_{1}}(x), \min \left(\mu_{M_{2}}(y)\right)\right]\right.$

or

$V\left(M_{2} \geq M_{1}\right)=\operatorname{hgt}\left(M_{1} \cap M_{2}\right)=\mu_{M_{2}}(d)= \begin{cases}1, & \text { if } m_{2} \geq m_{1} \\ 0, & \text { if } l_{2} \geq u_{2} \\ \frac{l_{1}-u_{2}}{\left(m_{2}-u_{2}\right)-\left(m_{1}-l_{1}\right)}, & \text { otherwise }\end{cases}$

Fig. 2 shows the way we perform the computations,

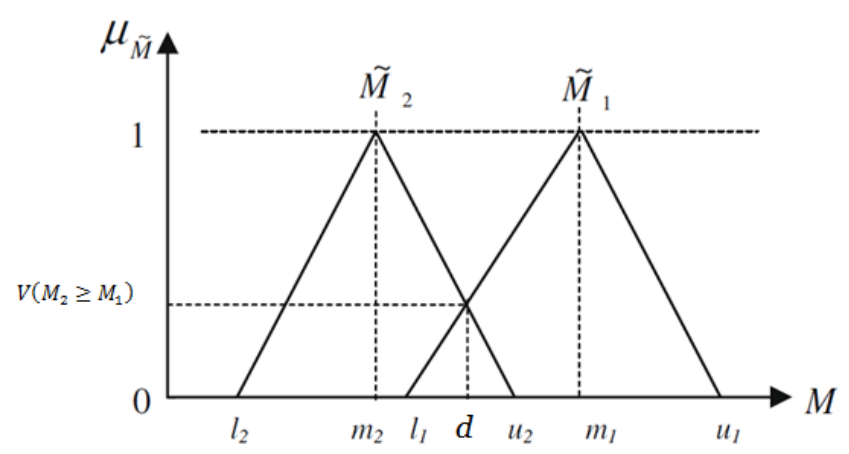

Fig. 2. Comparing two fuzzy numbers $M_{1}$ and $M_{2}$

Step 3. A big fuzzy number is also defined as follows,

$V\left(M \geq M_{1}, M_{2}, \ldots, M_{k}\right)=V\left[\left(M \geq M_{1}\right),\left(M \geq M_{2}\right), \ldots,\left(M \geq M_{k}\right)\right]=\min V\left(M \geq M_{i}\right) \quad i$
$=1,2, \ldots, k$

Suppose we har $V 1$

$d\left(A_{i}\right)=\min V\left(S_{i} \geq S_{k}\right) \quad k=1,2_{\mathrm{d}},, n ; k \neq i$

and the weighting vector $\mathrm{W}$ as follows,

$W=\left(d\left(A_{1}\right), d\left(A_{2}\right), \ldots, d\left(A_{n}\right)\right)^{T}$

Step 4. We normalize the vector using the following 
$W=\left(d\left(A_{1}\right), d\left(A_{2}\right), \ldots, d\left(A_{n}\right)\right)^{T}$

In order to study the relationships and the effects of various criteria on each other we have used the previous studies. For instance, when current ratio increases, quick ratio will increase too. An increase on debt ratio will increase ownership ratio and with an increase on profit margin and asset turnover, we expect an increase on return on asset too. According to Lee et al. (2008), when a firm expects more fixed cash flow for future, there will be more dividend. In addition, any firm with higher ownership ratio will create more market value. In order to validate the questionnaire, we have asked some expert to give their insights on the questionnaire and in overall the results of questionnaire was validated by them. Fig. 3. shows details of our relationships among network based on the implementation of fuzzy ANP (FANP).

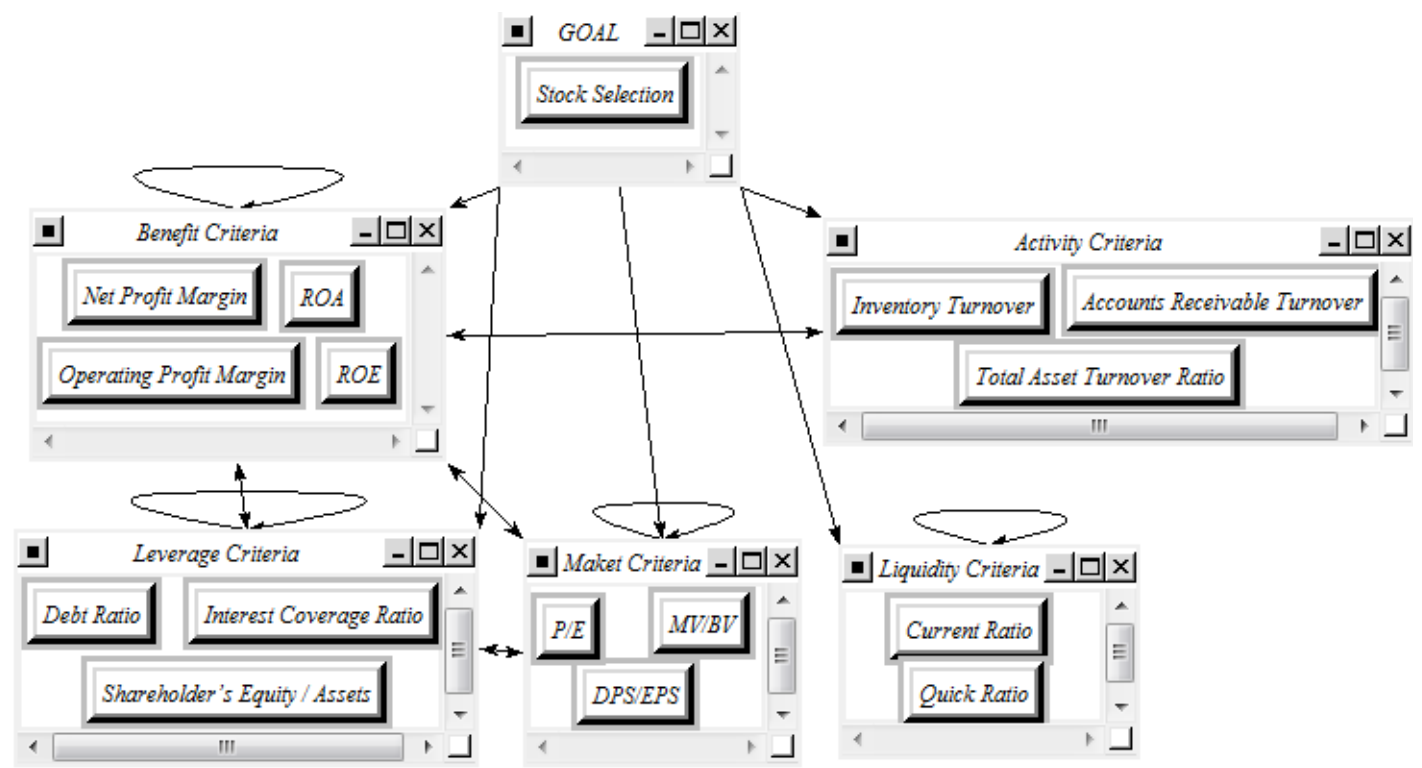

Fig. 3. Network of relationships between clusters and criteria (super decisions software)

Table 2 show all criteria along with the weights resulted from the implementation of FANP.

\section{Table 2}

The results of FANP

\begin{tabular}{llc}
\hline criteria & Ratios & Weights \\
\hline \multirow{4}{*}{ profitability criteria } & ROA & 0.107 \\
& ROE & 0.122 \\
& Net Profit Margin & 0.176 \\
& Operating profit margin & 0.144 \\
\hline \multirow{2}{*}{ liquidity criteria } & Current Ratio & 0.015 \\
& Quick Ratio & 0.013 \\
\hline \multirow{3}{*}{ leverage criteria } & Debt Ratio & 0.066 \\
& Shareholder's Equity to Total Assets Ratio & 0.053 \\
& Interest Coverage & 0.016 \\
\hline \multirow{3}{*}{ activity criteria } & Accounts Receivable Turnover & 0.027 \\
& Inventory Turnover & 0.023 \\
& Total Asset Turnover & 0.011 \\
\hline \multirow{3}{*}{ market criteria } & MV/BV & 0.094 \\
& P/E & 0.056 \\
\hline & $d \quad$ & 0.076 \\
\hline
\end{tabular}




\section{VICOR method}

This method is based on compromise planning on multi criteria decision making problem and it is normally used for problems with conflicting criteria. The implementation of VIKOR has the following stages,

Consider a decision making problem where there are $\mathrm{m}$ criteria and $\mathrm{n}$ alternative, we first form a matrix as follows,

$\mathrm{D}=\left[\begin{array}{ccc}\mathrm{x}_{11} & \cdots & \mathrm{x}_{1 \mathrm{n}} \\ \vdots & \ddots & \vdots \\ \mathrm{x}_{\mathrm{m} 1} & \cdots & \mathrm{x}_{\mathrm{mn}}\end{array}\right]$

where $x_{i j}$ is the performance of alternative $j,(j=1, \cdots, n)$ in terms of criteria $i,(i=1, \cdots, m)$. We next normalize the components as follows,

$\mathrm{F}=\left[\begin{array}{ccc}\mathrm{f}_{11} & \cdots & \mathrm{f}_{1 \mathrm{n}} \\ \vdots & \ddots & \vdots \\ \mathrm{f}_{\mathrm{m} 1} & \cdots & \mathrm{f}_{\mathrm{mn}}\end{array}\right]$

where

$f_{i j}=\frac{x_{i j}}{\sqrt{\sum_{i=1}^{m} x_{i j}^{2}}}$

Next, we have to determine the relative importance of each criteria as $W=\left[w_{1}, \cdots, w_{n}\right]$ along with the best and the worst possible values in the matrix as follows,

\begin{tabular}{ccc}
\hline Criteria & The worst & The best \\
\hline Positive & $\mathrm{f}_{\mathrm{i}}^{-}=\operatorname{minf}_{\mathrm{ij}}$ & $\mathrm{f}_{\mathrm{i}}^{*}=\max _{\mathrm{ij}}$ \\
Negative & $\mathrm{f}_{\mathrm{i}}^{-}=\max \mathrm{f}_{\mathrm{ij}}$ & $\mathrm{f}_{\mathrm{i}}^{*}=\min _{\mathrm{ij}}$ \\
\hline
\end{tabular}

The utility (S) and regret (R) measures are calculated as follows,

$$
\begin{aligned}
& S_{i}=\sum_{j=1}^{n} w_{j} \frac{f_{j}^{*}-f_{i j}}{f_{j}^{*}-f_{j}^{-}} \\
& R_{i}=\max \left[w_{j} \frac{f_{j}^{*}-f_{i j}}{f_{j}^{*}-f_{j}^{-}}\right] .
\end{aligned}
$$

VIKOR index $(\mathrm{Q})$ is calculated as follows,

$$
\begin{aligned}
& \mathcal{Q}_{i}=v \frac{S_{i}-S^{-}}{S^{*}-S^{-}}+(1-v) \frac{R_{i}-R^{-}}{R^{*}-R^{-}} \\
& R^{*}=\max R_{i}, R^{-}=\min R_{i}, S^{*}=\max S_{i}, S^{-}=\min S_{i}
\end{aligned}
$$


where $\frac{S^{*}-S^{-}}{S_{i}-S^{-}}$is distance from ideal situation and $\frac{R^{*}-R^{-}}{R_{i}-R^{-}}$is the distance from undesirable situation and parameter $v$ is determined based on an agreement from decision makers. Next we have to order $\mathrm{R}, \mathrm{S}$ and $\mathrm{Q}$ in three groups in non-decreasing order and finally choose the appropriate alternative. In group $\mathrm{Q}$, any alternative with the following criteria is chosen,

condition 1. If alternative $A_{1}$ and $A_{2}$ are the best alternative in group $\mathrm{Q}$ and $\mathrm{n}$ represents the number of alternatives we have,

$\mathcal{Q}\left(A_{2}\right)-\mathcal{Q}\left(A_{1}\right) \geq \frac{1}{n-1}$

Condition 2. Alternative $A_{1}$ must, at least, be superior in either of $\mathrm{R}$ and $\mathrm{S}$ group.

\section{Portfolio optimization}

Let $W_{i}$ be the portion of asset $i, r_{i}$ be the return of investment in asset $i$ and $\sigma_{i j}$ be the covariance between asset $i$ and asset $j$ and finally let $R$ be the maximum desirable return. The Markowitz (Markowitz, 1952) theorem solves the following optimization problem.

(Model 1) $\min \sum_{\mathrm{i}=1}^{\mathrm{N}} \sum_{\mathrm{j}=1}^{\mathrm{N}} \mathrm{w}_{\mathrm{i}} \mathrm{w}_{\mathrm{j}} \sigma_{\mathrm{ij}}$

subject to

$\sum_{i=1}^{N} w_{i} r_{i}=R$

$\sum_{i=1}^{N} w_{i}=1$

$0 \leq \mathrm{w}_{\mathrm{i}} \leq 1 \mathrm{i}=1,2, \ldots, \mathrm{N}$

The optimal solution of Model (1) needs to be evaluated based on different criteria and the fist one is Sharpe ratio, which is calculated as follows,

$S_{\mathrm{p}}=\frac{\mathrm{TR}_{\mathrm{p}}-\mathrm{R}_{\mathrm{f}}}{\mathrm{SD}_{\mathrm{p}}}$

where $\mathrm{TR}_{\mathrm{p}}$ is the average return, $\mathrm{R}_{\mathrm{f}}$ is the risk free asset and $\mathrm{SD}_{\mathrm{p}}$ is the standard deviation. Treynor $\left(T R_{\mathrm{p}}\right)$ is another criteria to measure the performance of an alternative and it is calculated as follows,

$T R_{\mathrm{p}}=\frac{\mathrm{TR}_{\mathrm{p}}-\mathrm{R}_{\mathrm{f}}}{\beta_{\mathrm{p}}}$, 
where $\beta_{p}$ is the systematic risk. Finally, Jensen ratio is calculated as follows,

$\alpha_{P}=E\left(R_{i}\right)-\left[R_{f}+\beta_{P}\left(E\left(R_{i}\right)-R_{m}\right)\right]$

where $E\left(R_{i}\right)$ is the expected return of the portfolio, $R_{m}$ is the return of market.

\section{The results}

In this section, we present details of the implementation of TOPSIS and VIKOR method for the case study of the proposed model of this paper. To measure the efficiency of the proposed model we compute Sharpe, Treynor and Jensen ratios. Table 3 shows details of the results of the implementation of the three models for these three ratios when Markowitz theorem has been adapted.

Table 3

The performance of the portfolio for the implementation of Markowitz theorem over the period 20072010

\begin{tabular}{ccc}
\hline & \multicolumn{2}{c}{ Method } \\
& VIKOR & TOPSIS \\
\hline Sharpe & 0.35516 & 0.35505 \\
Treynor & 6.26072 & 6.24544 \\
Jensen & 2.02414 & 2.02296 \\
\hline
\end{tabular}

In order to evaluate the performance of the proposed model for future we have considered the first 15 best assets and repeated our calculation and the results are summarized in Table 4.

Table 4

The performance of the portfolio for the implementation of Markowitz theorem over the period 20102011

\begin{tabular}{|c|c|c|}
\hline & \multicolumn{2}{|c|}{ Method } \\
\hline & VIKOR & TOPSIS \\
\hline Sharpe & 0.77484 & 0.77447 \\
\hline Treynor & 6.03208 & 5.83313 \\
\hline Jensen & 3.01191 & 2.94115 \\
\hline
\end{tabular}

As we can observe from the results of Table 4, the implementation of VIKOR yields better results in terms of three performance criteria. Next we used the weights calculated by TOPSIS and VIKOR for 15 best alternatives and normalized them. Table 4 shows details of our computations for these three ratios,

Table 5

The performance of the portfolio using normalized data over the period 2007-2010

\begin{tabular}{ccc}
\hline & & Method \\
& VIKOR & TOPSIS \\
\hline Sharpe & 0.08247 & 0.08202 \\
Treynor & 0.66781 & 0.65848 \\
Jensen & -0.19742 & -0.20818 \\
\hline
\end{tabular}


Again, as we realize that VIKOR provides better results than TOPSIS in terms of all three measures. In terms of predicting the performance for 2010-2011 period we used the data for the 15 best performers and the results are summarized in Table 6 as follows,

\section{Table 6}

The performance of the portfolio for the first 15 best performers over the period 2010-2011

\begin{tabular}{ccc}
\hline & & Method \\
& VIKOR & TOPSIS \\
\hline Sharpe & 0.34123 & 0.30225 \\
Treynor & 3.47022 & 3.09159 \\
Jensen & 1.50580 & 1.24305 \\
\hline
\end{tabular}

One more time, we can observe that VIKOR method represents better results compared with TOPSIS.

\section{Conclusion}

One of the most important issues in asset management is to consider appropriate criteria for asset allocation. In this paper, we have proposed a new method based on the adaptation of TOPSIS and VIKOR for asset ranking. The proposed model of this paper used five groups of financial ratios as criteria used in both TOPSIS and VIKOR techniques. We have applied the proposed model of this paper for a real-world case study from Tehran Stock Exchange. We have compared the performance of the proposed model in two cases, in the first case, we used Markowitz theorem for the initial asset allocation and then used TOPSIS and VIKOR techniques to rank the results. The performances of VIKOR and TOPSIS have been validated using Sharpe, Treynor and Jensen and the results indicate that all three measures were better for our case study in VIKEOR compared with TOPSIS. We have also used the weights calculated by TOPSIS and VIKOR for 15 best alternatives and normalized them. The results of the implementation of TOPSIS and VIKOR have been compared using three measures and the results were the same as the first case.

\section{References}

Amiri, M., Shariatpanahi, M., \& Banakar, M.H. (2010). Portfolio selection with The use of MCDM. Quarterly Journal of Securities Exchange

Brigham, E.F., \& Ehrhardt, M.C. (2007). Financial Management: Theory and Practice, by, $12^{\text {th }}$ ed., Thomson South Western.

Tiryaki, F., Ahlatcioglu, B. (2009). Fuzzy portfolio selection using fuzzy analytic hierarchy process. Information Sciences, 179(1-2), 53-69.

Chang, D. Y. (1992). Extent analysis and synthetic decision, optimization techniques and applications, Singapore: World Scientific, 352.

Chang, D. Y. (1996). Applications of the extent analysis method on fuzzy AHP. European Journal of Operational Research, 95, 649-655.

Chang, C. H., Lin, J. J., Lin, J. H., \& Chiang, M. C., (2010). Domestic open-end equity mutual fund performance evaluation using extended TOPSIS method with different distance approaches. Expert systems with applications, 37, 4642-4649.

Chen, C.T., \& Hung, W.Z. (2009). A new decision-making method for stock portfolio selection based on computing with linguistic assessment. Journal of Applied Mathematics and Decision Sciences, ID 897024.

Ehrgott, M., Klamroth, K., \& Schwehm, C. (2004). An MCDM approach to portfolio optimization. European Journal of Operational Research, 155(3), 752-770 
Ertuğrul, İ, \& Karakaşoğlu, N. (2009). Performance evaluation of Turkish cement firms with fuzzy analytic hierarchy process and TOPSIS methods. Expert Systems with Applications, 36(10), 702715.

Enea, M., \& Piazza, T. (2004). Project selection by constrained fuzzy AHP. Fuzzy Optimization and Decision Making 3, 39-62.

Fama, E.F., French, K.R, K. (1992). The cross-section of expected stock returns. Journal of Finance, 47(2), 427-466.

Lee, A.H.I., Chen, W-C., \& Chang, C-J. (2008). A fuzzy AHP and BSC approach for evaluating performance of IT department in the manufacturing industry in Taiwan. Expert systems with application, 34, 96-107.

Lee, W.S., Huang, A.Y., Chang, Y.Y., \& Cheng, C.M. (2011). Analysis of decision making factors for equity investment by DEMATEL and Analytic Network Process. Expert Systems with Applications, 38(7), 8375-8383.

Jones, C. (1998). Investment Analysis and Management. $6^{\text {th }}$ ed., John Willey \& Sons.

Kahraman, C., Ruan, D., \& Tolga, E. (2002). Capital budgeting techniques using discounted fuzzy versus probabilistic cash flows. Information Sciences, 142, 57-76.

Markowitz, H.M. (1952). Portfolio selection. Journal of Finance, 77-91.

Meziani, A.S. (2003). Assessing the effect of investment barriers on international capital flows using an expert-driven system. Multinational Business Review, 11(2), 49 - 74.

Ross, S., Westerfield, R., Jordan, B., \& Roberts, G. (2002). Fundamental of Corporate Finance, 4th ed, McGraw-Hill.

Reilly, F. K, Brown, K. C., (2003). Investment Analysis and Portfolio Selection, $6^{\text {th }}$ ed.

Reilly, F., \& Norton, E. (2006). Investments. $7^{\text {th }}$ ed., South Western Ohio, Thomson.

Saaty T.L. (1980). The Analytic Hierarchy Process. McGraw-Hill, New York.

Saaty T.L. (1996a). The Analytic Network Process. RWS Publications, Expert Choice, Inc.

Saaty, T.L. (1996b). Decision Making with Dependence and Feedback: The Analytic Network Process. RWS Publications, Pittsburgh, PA. 